\title{
A leitura literária como saber interdisciplinar: considerações a partir da prosa poética de Bartolomeu Campos de Queirós
}

The literary reading as interdisciplinary knowledge: considerations from the prose poetry of Bartolomeu Campos de QueirósThe book and it's mediation in childhood

\section{Hellenice Ferreira}

\section{Anna Paula Soares Lemos}

Universidade do Grande Rio - UNIGRANRIO - Duque de Caxias - Rio de Janeiro - Brasil

\begin{abstract}
Resumo: Este artigo tenciona apresentar a interdisciplinaridade presente na produção literária do escritor de Bartolomeu Campos de Queirós, através das obras O peixe e o pássaro (1974), Pedro (1983), Mário (1982), Ciganos (1982), Minerações (1991), De não em não (1998), Sei por ouvir dizer (2007), e Menino inteiro (2009), procurando a partir deste particular, demonstrar a leitura literária como constituída e produtora de saberes vários. A escolha do autor ampara-se na assertiva de Antonio Cândido (1987) que lembra "o fato da produção literária ter surgido em Minas, no século XVIII, com um acentuado cunho de universalidade". Mineiro, Queirós universaliza sua escrita prenhe de saberes transmutados em poesia, de modo a ser lido aqui ou alhures sem prejuízo de sentido, e a fortiori compreendida com produto dos sentires humanos, uma escrita, por assim dizer, inter (e intra) geográfica. Para chegarmos à sua produção, convidamos o leitor a breve passeio pela produção literária dedicada à criança, mas que envolve leitores de todas as idades.
\end{abstract}

Palavras-chave: Interdisciplinaridade; Literatura infantil; Literatura infanto-juvenil; Leitura Literária; Bartolomeu Campos de Queirós.

Abstract: This article intends to present the interdisciplinarity present in the literary production of the writer of Bartolomeu Campos de Queirós, through the works O peixe e o pássaro (1974), Pedro (1983), Mario (1982), Ciganos (1982), Minerações (1991), De não em não (1998), Sei por ouvir dizer (2007), and Menino inteiro (2009), looking from this particular, to demonstrate the literary reading as constituted and producer of several knowledges. The author's choice is based on the assertion of Antonio Cândido (1987), which recalls "the fact that literary production appeared in Minas in the eighteenth century with a marked universality." From state of Minas Gerais, Queirós universalizes his writing pregnant with knowledge transmuted into poetry, in order to be read here or elsewhere without prejudice of meaning, and a fortiori understood with the product of human sentiments, a writing, so to speak, inter (and intra) geographical. To reach its production, we invite the reader to take a brief tour of the literary production dedicated to the child, but involving readers of all ages.

Keywords Interdisciplinarity; Children's literature; Children's literature; Literary Reading; Bartolomeu Campos de Queirós. 


\section{A leitura literária como caminho para saberes vários}

Desde que Monteiro Lobato (1882-1948) buscou livros que falassem de nossa terra para as crianças, no que resultou em o nascimento de Reinações de Narizinho (1931) e uma extensa coleção de histórias passadas num sítio - passível de ser o de cada leitor, em lugar real ou imaginário - que a literatura, classificada comercialmente para criança, em nosso país fisga o leitor adulto.

Importa ressaltar que falo de literatura, e não das obras didatizantes, produzidas para ensinar e reforçar conteúdos elencados pela escola. Trato da literatura, a que se deve referir "em caixa alta e negrito", que nos faz refletir, e não se presta ensinar, menos ainda imitar a escola, ressaltando seus conteúdos base. Refiro-me a literatura que, sendo arte, permite a criação do leitor. Deixa-Ihe espaço para colori-la e adjetivá-la a seu bel prazer. Atribui ao leitor o papel juiz de valor, e não se lhe oferece como maravilha do mercado editorial e capacitadora. Literatura que se oferece e pronto, como toda obra de arte.

Ao desejar fazer livros para as crianças poderem morar - "Ainda acabo fazendo livros onde as nossas crianças possam morar" - e tornar seu intento real, Lobato dialoga com a criança que todos fomos e preenche nossas carências com histórias de uma avó que respeita a liberdade de seus netos, uma tia-torta contadora de contos populares, composta de doçura, medo e amor, um tio vizinho, sempre apostos, bonecos e bichos falantes, com os quais saímos do lugar comum do cotidiano e voamos pirlimpinpins afora, para espaços intrigantes, afetivos, inovadores, brincantes. E, entre torpores e escolhas ousadamente pensadas, apreendemos o mundo, desaprendendo formas e inventando formas.

É certo, não devo deixar de dizer, que toda literatura o faz, e para falar da infantil, lembro que também percorremos as miudezas do mundo de Polegarina, dançamos enlouquecidos com Sapatinhos Vermelhos, e choramos os fósforos não vendidos da menina, todas nascidas de Andersen
(1805-1875), da mesma forma com que somos queimados vivos com a velha colecionadora de livros criada por Ray Bradbury (1920-2012) para a obra Fahrenheit 451, e nos lambuzamos em A Fantástica Fábrica de Chocolate, de Road Dahl (1916-1990), mas desejo demarcar o solo literário brasileiro, e por isso começo com Lobato, pai da literatura classificada como infantil.

O fato de me reportar à literatura infantil e infanto-juvenil como classificada e não criada para tal público, tem sua fundamentação numa assertiva da poeta mineira Henriqueta Lisboa (1901-1985), lembrada inúmeras vezes por Bartolomeu Campos de Queirós, também escritor nascido nas Gerais, de quem transcrevo a seguinte citação

Eu convivi durante muito tempo com uma grande poetisa brasileira que foi Henriqueta Lisboa. Henriqueta também me deu uma pista muito grande para o meu trabalho, quando disse que a natureza era também muito sábia e a natureza nunca tinha feito uma árvore para adulto e uma árvore para criança; que a natureza nunca tinha feito um rio para adulto e um rio para criança; que não havia um sol para adulto e não havia, tampouco, um sol para criança. Então por que nós estávamos querendo fazer uma literatura para adultos e uma literatura para criança? (QUEIRÓS, 2012, p.56)

Ao demarcar a literatura destinada a esta fase de leitores, faço-o com o único objetivo de restringir meu objeto de estudos e com a intenção de convidar o leitor adulto a desviar seu olhar, com atenção, para estas publicações, ainda distanciadas da academia, apesar de demasiado intrigantes e provocadora de novos pensares.

Pós Lobato, muitos dos que se aventuraram pela escrita de obras colocadas nesta prateleira Ruth Rocha, Sylvia Orthof e Lygia Bojunga, por exemplo - nos ofereceram, e oferecem um enredado coletivo de saberes através de literatura.

Eis do que se compõem as literaturas. Eis, portanto, o que nos compõe quando partilhamos destas criações, quando lemos literaturas: saberes livres de cobranças, construídos pelas sensações e reflexões que despertam de modo individual, e coletivamente quando lidas em rodas destinadas a este fim 
Ademais, como afirmou Queirós (2012) "A leitura literária é um direito e que ainda não está escrito", e por ser direito precisa ser embandeirado por todos os que, ocupantes das academias, o reconheçam como tal. Pesquisadores atentos a importância de coletivizar possibilidades, escancarar portas e janelas pelas quais a leitura literária possa ser absorvida pela maioria da sociedade que, atrelada às emergências da vida cotidiana, compelida a atender necessidades básicas, se vejam impedidas de desfrutar das academias.

Aliás, grande parte do povo brasileiro sequer sabe que os espaços de reflexão das academias deveriam ser ocupados por todas e todos. As urgências os alijam deste processo ainda nos bancos escolares do ensino fundamental.

Abertas as portas da literatura, democratizado o direito à leitura literária, poderíamos dialogar em igualdade de condições, aprendendo com o saber popular, sem restringir o acadêmico a poucos.

Neste sentido, há mais de vinte anos venho observando na área profissional onde atuo - as escolas de ensino fundamental - que mesmo as professoras e professores se distanciam deste lugar, o lugar de leitores de literatura, e por este motivo, se encarceram no frenesi administrativo-pedagógico de cumprir datas, quantificar saberes ofertados (muitas vezes de modo unilateral) às suas alunas e alunos, se afastando do papel de articulares, de seres para o diálogo que deveriam ser, e deveriam estimular que seus ouvintes fossem.

Por outro lado, nesta mesma seara profissional, pude ver profissionais transmutando seus cotidianos a partir da promoção de leituras literárias. Professoras e professores que, destinados a trabalhar com a literatura pela fruição, se tornam mais ouvintes, preocupados igualmente em dar espaço para a fala dos discentes, independente das idades que tenham. Quando proponho que a leitura literária é constituída por saberes interdisciplinares, incluo o saber ouvir e estimular a fala como habilidades esquecidas pela escola, lugar da minha fala e experiência.
Ouso ainda dizer que, ao lado da interdisciplinaridade e advinda da vivência coletiva das leituras literárias, reside a inter-aprendizagem, possível quando os saberes são partilhados de modo circular, de modo que todos possam ser provocadores uns dos outros, mas esta questão eu guardo para novo artigo, mais detidamente destinado ao tema.

Por agora, trago uma vivência que ressalta o que afirmo:

No ano letivo de 1999, às voltas com jovens recentemente agrupados em turmas de EJA compostas essencialmente por pessoas da terceira idade, iniciamos o trabalho de leituras literárias oferecendo poesias. $\mathrm{Na}$ terceira semana de atividade, mesmo sem haver conquistado o coletivo para a escuta e discussão das poesias oferecidas, uma das jovens lideres pediu para ler um texto seu. A leitura, que primeiro motivou provocações por parte dos de sua idade, despertou interesse dos mais velhos que foram elogiando sua coragem de ler publicamente o que escrevera, sem medo dos julgamentos. Elogiaram também o texto em si, que se tratava de uma poesia. A jovem aluna, encorajada pelas palavras ouvidas, contou sua história, suas inúmeras reprovações escolares, e há quanto tempo escrevia poesia sem mostrar a ninguém, justificando a decisão de mostrá-la para o grupo, após ter ouvido, em aula anterior, a leitura da obra Mário, de Bartolomeu Campos de Queirós. Disse que também colecionava pequenas coisas e sempre fora criticada por tamanha desimportância de ato, mas com a personagem do livro, se sentiu acompanhada e estimulada. Sua fala transcorreu fluida e emocionada, acalmando os ânimos dos que se recusavam participar, e sequer aceitavam que ela, que era liderança, se envolvesse na aula. Naquela noite a atividade com leitura literária foi estendida, e despertou outras falas e escutas. Ao final da aula, oitenta por cento da turma falou sobre suas cartas, poesias, cantigas, silêncios e desejos, com inteireza, levando a escola a organizar um sarau onde suas produções fossem lidas, por discentes e docentes.

Afastados do espaço escolar, mas prenhes de vivências pessoais, e saberes populares estruturados pela vida, estas alunas e alunos, jovens e adultos, puderam, através da leitura literária, se perceber como seres produtores de saberes vários. $\mathrm{E}$ mais, puderam ver a amplitude destes saberes (também podiam escrever poesias), e comunicá-los sem o medo que a avaliação impõe. Perceberam-se iguais, 
participantes de uma aprendizagem construída de modo circular, pois que cada leitor é também um escritor de suas percepções, dúvidas, proposições e conclusões.

Esta reflexão não se mostrou diferente em encontros com discentes crianças.

Em 2006, durante uma das rodas de leituras que realizei com uma turma de quarto ano de escolaridade, uma menina de nove anos verbalizou seu desassossego, dizendo-me "Porque você não deixa a gente lê? Só você que lê. A gente também quer ler e falar depois, e não ter que esperar você acabar de ler para falar. Deixa a gente lê cada um numa hora, e aí você escuta e fala depois também".

A pequena reivindicava seu direito de protagonista na leitura, e proposições iniciais. Provavelmente se estivéssemos numa aula convencional, ela não se colocaria, porque nesta situação a origem do saber e da fala é destinado a quem está à frente, ao que fala para ser ouvido, e não ao que convida a discutir.

É por este motivo, por estas experiências supracitadas, que para além de enxergar a leitura literária como saber interdisciplinar, também a considero promotora de inter-aprendizagem, e dentre estas aprendizagens a de ouvir e falar, oportunizadas através de momentos em que todos podem ser provocadores de elucubrações. $O$ indivíduo que excursiona pela palavra do outro, lendo-a ou ouvindoa ser lida, encontra a sua própria, deseja ofertá-la, e precisa ter este desejo atendido. É seu direito. Na escola, sobretudo na de ensino fundamental, apenas observei este momento sendo possível em rodas de leituras. E leituras literárias. A literatura, autoral ou popular, forma leitores-ouvintes, discentes ou docentes, e os instrumentaliza para o diálogo, sem 0 qual a aprendizagem não se completa, como nos faz pensar Paulo Freire ao anotar que

Uma das tarefas essenciais da escola, como centro e produção sistemática de conhecimento, é trabalhar criticamente a inteligibilidade das coisas e dos fatos e a sua comunicabilidade. É imprescindível, portanto, que a escola instigue constantemente a curiosidade do educando em vez de "amaciála" ou "domesticá-la". É preciso por outro lado, e, sobretudo, que o educando vá assumindo o papel de sujeito da produção de sua inteligência do mundo e não apenas o de receber da que lhe seja transferida pelo professor. (Freire, 1996, p. 121)

E pude ver que quem lê Monteiro Lobato, quer comunicar seus sítios. Quem entrevê as artimanhas políticas de Ruth Rocha (1931-) em seu $O$ que os olhos não vêem, traça paralelo e se inflama do desejo de dizer. Diante de Mudanças no galinheiro mudam as coisas por inteiro, de Sylvia Orthof (1932-1997), não há como se furtar pensar o patriarcado. Ao passearmos com $A$ bolsa amarela, de Lygia Bojunga (1932-) também queremos trocar de lugar e experimentar outras possibilidades.

Poderia citar outras tantas escritoras e escritores de literatura infantil e infanto-juvenil cujas palavras acordaram a voz de docentes e discentes, leitores com os quais convivo, levando-os muito além do que supunham leitura após leitura. Todavia elegi algumas obras Bartolomeu Campos de Queirós, que, para além de fornecerem os instrumentos de escuta e fala que cito, e se mostrarem repletas de possibilidades interdisciplinares, o fazem através da prosa poética, gênero perspicaz e intenso, que possibilita variados níveis de leitura e compreensão, não excluindo o leitor iniciante, mas exigindo do leitor maduro mergulho nas entrelinhas, ampliando espaços para desenvolvimento da sensibilidade em cada vivência leitora.

Para além deste motivo, a escolha do autor ampara-se na assertiva de Antonio Cândido (1987) ao lembrar que "o fato da produção literária ter surgido em Minas, no século XVIII, com um acentuado cunho de universalidade; e o fato dos mineiros gostarem de literatura na primeira pessoa" são paradoxos que formaram a identidade literária do Brasil.

Mineiro, Queirós universaliza sua escrita prenhe de conceitos transmutados em poesia, de modo a ser lida aqui ou alhures sem prejuízo de sentido, e a fortiori compreendida como produto dos sentires humanos, uma escrita, por assim dizer, inter (e intra) geográfica, sobre a qual convido o leitor que chegou até aqui, a se debruçar com olhos de lince e com vagar de borboleta. 


\section{Contribuições da prosa poética de Bartolomeu Campos de Queirós}

\author{
Antes de iniciar 0 percurso dentre as \\ contribuições encontradas na produção de
} Bartolomeu Campos de Queirós, vale nos perguntar quem é Bartolomeu.

Ofereço suas próprias palavras à guisa de resposta

\begin{abstract}
Eu sou do interior de Minas, cheio de rezas, de crendices, essas coisas bem pesadas que são próprias de mineiro. E me contaram que eu demorei muito a falar e que ensinaram a minha mãe que para eu poder falar era bom dar água do sino em dia de chuva. Porque, além de aprender a falar, eu só ia falar na hora certa.

Escutei isso muito tempo na minha vida, talvez seja essa uma coisa que me levou, talvez, a falar pouco, aquela coisa que eu brinco sempre, que eu sou de família do interior e que a primeira cartilha que aprendi a ler foi o olhar do meu pai. Meu pai olhava pra gente e a gente sabia se podia comer mais um doce, se podia tomar mais um copo de groselha. Então aprendi a ler por aí. (...)

Eu acho que depois, com a formação também na área de filosofia, comecei a ter certeza de que meu olhar não esgota o que eu vejo, existem outras coisas além do que vejo e que só pode chegar lá pelo imaginário, não tem outro caminho. (QUEIRÓS, 2012, p.57)
\end{abstract}

E ainda as de Rui de Oliveira, ilustrador de renome em nosso país e fora dele, responsável, dentre tantos outros trabalhos, pelas imagens da abertura inicial e capitulares, do programa Sítio do Pica-Pau Amarelo, exibido por uma rede de TV na década de 1970, que, tendo sido amigo de Queirós, inicia suas considerações sobre ele, situando-o no rol dos poetas brasileiros, mas demarcando seu estilo em prosa

Acredito que os poetas - e é a própria história da literatura que nos diz - representam, mais do que qualquer outra linguagem artística, a alma de um povo, de uma nação. Eles corporificam as civilizações, os grandes feitos e tragédias dos homens. Originalmente associada à música, a poesia é a voz autêntica e canora das sociedades e dos idiomas - seu momento máximo de expressão e beleza. Nenhum país se forma sem seus poetas. Assim foi Homero para os gregos, Milton para os ingleses, Whitman para os americanos, Camões para os portugueses,
Pushkin para os russos. A multifacetada alma brasileira, nós a encontraremos uníssona, homogênea em sua diversidade na poesia de Gregório de Mattos, Gonçalves Dias, Castro Alves, Carlos Drummond de Andrade e Manuel Bandeira, todos estes, e muitos outros, compõem o mosaico de nossa alma. Esta é a introdução que gostaria de fazer para falar da poesia de Bartolomeu Campos de Queirós, até pelo fato de sua prosa ser elaborada, a meu ver, em forma poética. (OLIVEIRA, 2012, p. 45)

De certo por este olhar, o da imaginação, e pela prosa poética que o compõe, que sua obra inaugural em literatura, $O$ peixe e $o$ pássaro aponta 0 diverso caminho de tentar compreender o mundo e sua incompletude. Através do desejo de amoraproximação impossível entre as personagens, sua vida de educador pesquisador, comprometido com suas questões, mas que as discutia em solo distante do seu, fez nascer uma obra que fala de amor e distâncias, de amar apesar das impossibilidades, com maestria.

Como expatriado, em exílio auto-imposto para prosseguir seus estudos, Queirós inaugura uma literatura capaz de reunir elementos simples, observados com inteireza por olhos infantes, sem perder qualidade para leitores adultos, sobretudo os que não excluem as experiências de infância de suas vidas cotidianas.

Dizer do amor entre peixes e pássaros, é dizer que não há impedimentos para amar, como não o há para estudar, mas demonstra o quanto a vida é feita de escolhas, e o quanto ao preferir preterimos algo ou alguma coisa, sem deixar de querer bem a ambas. Esta prosa poética, em que se inaugura como escritor de literaturas, permite discussões filosóficas, que podem ser tratadas com crianças e adultos. Aliás, como poeta, Queirós alarga horizontes dialógicos a cada nova obra que traz a lume, com riqueza de argumentações filosóficas.

Vejamos em Pedro: o menino que tinha o coração cheio de domingo. Nesta obra, o autor recorre mais uma vez ao universo das pequenezas para acordar as densidades do simples e propor reflexões densas, apresentadas no regaço de metáforas suaves, que respeitam fases e maturidades de os possíveis leitores. 
Em imbricadas metáforas, aproxima as habilidades e buscas do menino Pedro pelas cores e aos voos de uma borboleta, às buscas humanas. $O$ diálogo possível nascido desta leitura, não apenas nos convida observar o microcosmo do inseto, seu universo e cores, como nos catapulta a auto-análise de nossas próprias vidas e quereres. "Domingo é dia em que a gente não quer nada e por isso acontece quase tudo", escreve o autor para também nos lembrar da importância do tempo para criar. Há que se ter tempo para pensar, espaço para a imaginação fluir, livre das amarras do tempo escasso da cotidianidade. Há que aquarelar nossos desejos e pensares sem as amarras das obrigações. Há que se observar as simplicidades que transformam em/com riquezas nossas vidas, deixando que pousem e se vão apreendendo e usufruindo com a fugacidade de cada momento. Vida-morte-vida, embebida de arte, são outras discussões possíveis.

Em obra anterior, Mário, o que menciono fica igualmente claro e demasiado marcado, quando, o menino protagonista após observar por dias um ninho de pássaros, produz a síntese da vivência em palavras. Afeito a coleções de pequenos objetos, Mário dedica seu olhar afetuoso de colecionador ao ovo gestado, até que é convidado a ver a mortenascimento do ovo-pássaro. $E$, como mencionei, oferece 0 produto desta vivência, numa poesia derramada sobre papel

\section{A POESIA \\ Engasgado na hera da janela um ninho de passarinho.}

Ovo fechado, envelope lacrado, carta plena para o mundo.

Depois, em todo tempo

e por todo voo,

circulará notícia sua.

(Hoje Mário é menino e poeta)

Prosseguindo as considerações apresento o trecho inicial de Ciganos

Eles deixaram a Índia, alguns dizem, em busca de um caminho para se chegar ao sol. Escutei de outros que eram filhos das grandes florestas e procuravam uma passagem para as minas de ouro do rei Salomão. Outros falavam que vinham das terras de Espanha ou das areias de Portugal. Cortaram o mar, guiados pelo brilho das escamas de sereias, escondidos nas noites.

Sem saber ao certo de onde vinham ou para onde iam, sei que os ciganos surgiam. (QUEIRÓS, 1982, p.1)

Um único povo é, em si, um desfile de povos e costumes, e o narrador, descreve o olhar de outro menino personagem - é preciso ressaltar que a infância marca a produção literária do autor - que se descobre desejoso de pousar em outras terras diferentes da sua

Foi no tempo dos ciganos que o conheci. Ele era como a madrugada: perto de acordar, mas ainda cheio de sono. Era um menino feito de coragem e medo.

Não sei bem de que paisagem ele havia nascido, nem com que paisagem ele andava sonhando. Mas não eram poucos os seus segredos, e seus olhos, estes eram líquidos como eram medrosos os seus gestos.

Lembro-me, contudo, de seu primeiro segredo: desejo escondido de ler a linha do horizonte e desvendar o mistério que diziam além dos mares e das montanhas.

Inúmeros diálogos são possíveis a partir da leitura destes breves parágrafos, e para quaisquer espaços e faixas etárias. A obra possibilita refletir sobre nossos saberes e faltas, permutando-os e buscando supri-los em outras bases, para além da conversa, se oferecidas professor-articulador.

Como o mar de montanha de suas Gerais, o autor preenche sua produção com densidades que provocam e emocionam, ensinam e ampliam nosso acervo de conteúdos sem didatizá-lo. Queirós não abre mão da arte que o compõe. Sua literatura é preenchida a óleos, águas fortes e aquarelas. Em andantes e allegros ma non troppo. Com argila e aço feitos palavras. Nunca uma cartilha.

Minerações e De não em não, são dois exemplos que trago para apresentar o panorama artístico de sua literatura.

No primeiro, convido o leitor a apreciar a ilustração de Paulo Bernardo Vaz (1949-) que longe de limitar-se reiterar a obra escrita, a amplia 


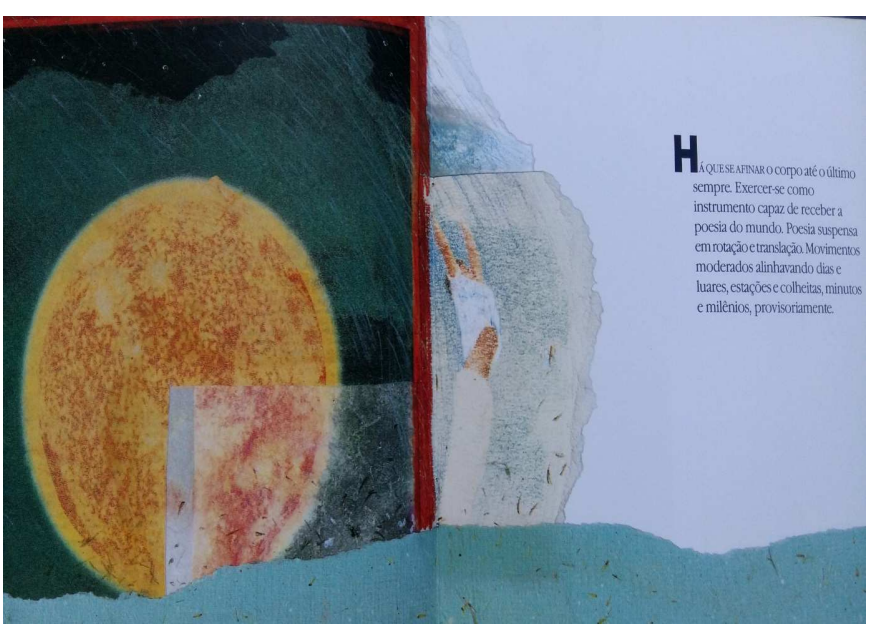

E se nesta estrofe somos convidados a somar o que sabemos sobre música, corpo e geografia para sorver a poesia-reflexão com inteireza, sem descuidar os olhos da imagem inquieta e convidativa do ilustrador, noutra o convite é para o reconhecimento de nossa incompletude

Há que se ser frágil o suficiente e reconhecerse inábil para inferir emendas na lei que equilibra as águas. Inábil para decretar outros mistérios ao destino das constelações. Inábil para escolher as cores dos crepúsculos. (QUEIRÓS, 1991, p.8)

Na obra De não em não, o tema é a fome, e ela é destilada e oferecida de modo ácido ao leitor. $\mathrm{E}$ sem concessões. Sua leitura desconstrói o lugar comum que classifica a leitura como prazer, fruição e deleite. Leitura também acorda incômodo, provocação e dor.

A família protagonista é visitada pela fome e convidada pela matriarca, após o sumiço-procura-poremprego do pai, a comer o reflexo da lua, servido em fatias. A mãe vê seus filhos morrendo, um a um, e por suas garras, os leitores, que, se maduros, lembrar-seão de Grande Sertão Veredas, O quinze e outros tantos, geográfica ou socialmente próximos, literariamente embandeirados de reflexões-denúncia sobre as desigualdades desse nosso farto país, são levados a olhar de perto desmedida dor, sem chances de virarem o rosto. Não lhes é permitido fingir que não vêem. A fome está lá, de braços dados com a morte e com a falta de opções. O descaso mata, e estamos todos implicados em seu desdobramento.

A cada obra vamos observando inúmeras possibilidades de conteúdos convencionais (levando em conta as grades curriculares) entrelaçados nas palavras poéticas, até que Bartolomeu nos convida a subverter tempos, conceitos e convencionalidades em Sei por ouvir dizer (2007), demonstrando que a literatura não é serviçal do ensino escolarizado, é antes instrumento de manuseio delicado, capaz de acordar saberes variados, imbricados por dentro de nós à nossa própria vida, em acordes que não nos cobra nota, e não nos permite disfarçar entendimento

A casa se mantinha de pé com apenas três paredes: um muro contra o vento, outro contra a chuva e mais outro impedindo o medo de entrar. A quarta parede não existia. Por ela entravam os convidados. Em cada parede, uma janela. Na primeira, ela se debruçava e sorria, olhando ao longe. Na segunda janela, ela chorava, olhando as coisas mais próximas. $\mathrm{Na}$ terceira ela escrevia cartas sobre a linha do horizonte. Usava três penas: uma pena de passarinho para falar de céu, uma pena de juiz para contar casos de terra. Com a outra pena, ela sentia pena de quem não sabia ler o livro da fantasia (QUEIRÓs, 2007, p. 09)

Aqui, de modo cristalino, o poeta ressalta as restrições impostas aos analfabetos funcionais. Informa seu lamento por saber-se impedido de comunicar-se com tantos. Esta inquietude o motivou a elaborar $O$ manifesto por um Brasil literário, pelo qual lutou até os últimos dias de sua vida. Nele expressa

Reconhecemos como princípio o direito de todos de participarem da produção literária. No mundo atual, considera-se a alfabetização como um bem e um direito. Isto se deve ao fato de que com a industrialização as profissões exigem que o trabalhador saiba ler. No passado, os ofícios e as ocupações eram transmitidos de pai para filho, sem interferência da escola.

Alfabetizar-se, saber ler e escrever tornou-se hoje condição imprescindível à profissionalização e ao emprego. A escola é um espaço necessário para instrumentalizar o sujeito e facilitar seu ingresso no trabalho. Mas pelo avanço das ciências humanas compreende-se com inerente a homens e mulheres a necessidade de dar corpo às suas capacidades inventivas. (...)

É o que a literatura oferece e abre a todo aquele que deseja entregar-se à fantasia. Democratiza-se assim o poder de criar, imaginar, recriar, romper o limite do provável. Sua fundação reflexiva possibilita ao leitor dobrar-se sobre si mesmo e estabelecer uma prosa entre o real e o idealizado. (Queirós, 2012, p.118) 
Dono de uma escrita densa, poética e sempre inaugural, Bartolomeu Campos de Queirós se oferece inteiro à causa da leitura literária. Contribui para que pudéssemos discorrer sobre variadas temáticas nas escolas, espaços de educação e rodas de leitura, mas sua intenção sempre foi a de libertar a palavra ao ouvido do leitor, de modo que ele próprio traçasse seus parecessem numa boa nova particular, escrita com palavras ou silêncios.

Em Menino Inteiro (2009) Queirós consegue reinaugurar um dos episódios mais conhecidos da cristandade, descrevendo deste modo a morte de Jesus Cristo

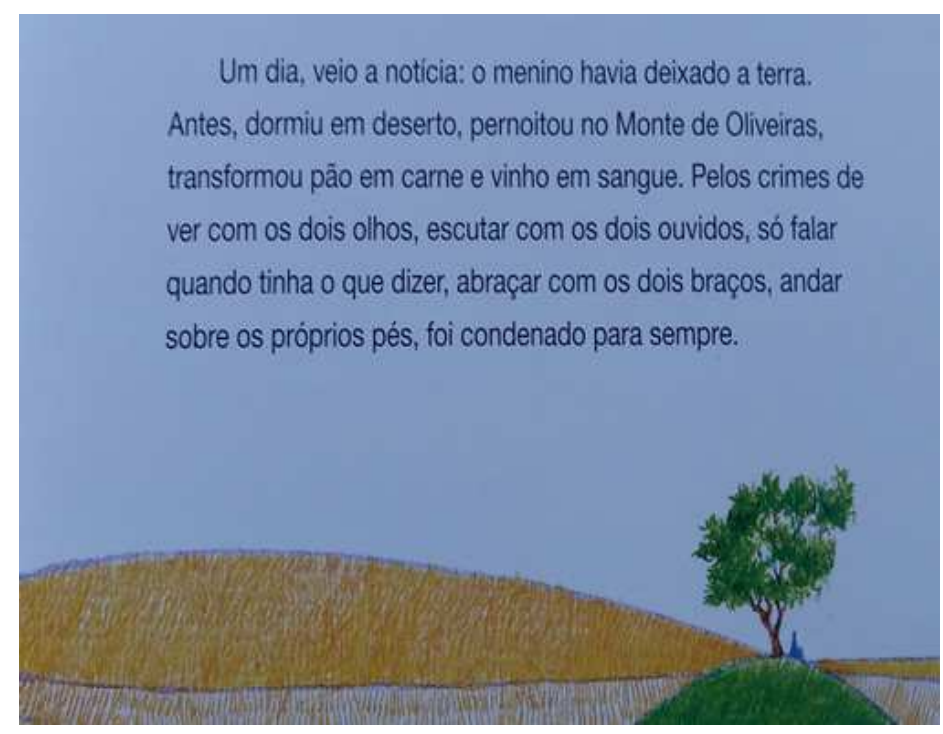

Como a metáfora utilizada para descrever o Cristo, ele próprio se ofereceu inteiro à literatura, e ainda nos convocou a instituí-la como direito, de modo a concorrermos para a construção de um país mais equitativo, e uma sociedade, portanto, mais justa, onde cada um possa, sorvendo da leitura literária, desfrutar do direito de idealizar outros cotidianos, em igualdade de condições.

\section{Conclusão}

Se compararmos a leitura literária à escuta de histórias ao pé da cama, suponho que a compreensão do que me propus neste artigo, transcorrerá naturalmente. Quando ouvíamos histórias, ação que há duas décadas era ato corriqueiro entre as famílias, nós aprendíamos sobre a origem das coisas, sobre importância do cuidado, com o outro e conosco, como os homens começaram a plantar e deixaram de serem nômades, como os sacis perturbam cavalos, etc. Nem todas as histórias correspondiam a um axioma, mas sempre aprendíamos sobre mais coisas do que a história em si, porque para saber um fato, precisávamos ouvir em que contexto se inseria. Os saberes estavam lá, interdisciplinares, oferecidos com leveza e prontos para serem discutidos em pé de igualdade.

A escola, imbuída de ensinar, compartimentalizou os saberes, instituiu que apenas professores são formadores, de cima para baixo, para quaisquer discentes, e criou métodos quantitativos para medir o tanto que absorveriam dos conteúdos apresentados, provocando limitações onde poderia haver aprendizagem natural e de modo circular.

Considero que o trabalho com a leitura literária, que no espaço em que atuo - escolas de ensino fundamental - é coordenado por professoras e professores especificamente destinados para tal, permite recuperar a fluidez com que as aprendizagens se davam na escuta de histórias ao pé da cama, tanto no sentido de permitir fala a todas e todos, quanto no de oportunizar a rotatividade dos saberes.

Não sendo uma disciplina formal o trabalho com a leitura literária permite a descentralização do poder de fala e mistura, no melhor dos sentidos, o acervo dos participantes. Portanto, considero sobremodo importante fortalecer estas ações, e apresentando parte da produção de Bartolomeu Campos de Queirós, tenciono contribuir para que mais profissionais desejem apropriar-se da literatura como instrumentos de ensinagem, para que as aprendizagens fluam de modo a permitir que saber e prazer sejam democratizados nos variados espaços de ensino, sobretudo nas escolas.

\section{Referências}

ANDERSEN, Hans Christian. Vinte e cinco contos de Andersen. Clube dos autores: Edição Digital, 2018. 
BOJUNGA, Lygia. A bolsa amarela. Rio de Janeiro: Casa Lygia Bjunga, 2012.

BRADBURY, Ray. Fahrenheit 451. Rio de Janeiro: Editora Globo, 2003.

CÂNDIDO, Antonio. A educação pela noite e outros contos. São Paulo: Editora Ática, 1989.

DAHL, Road. A fantástica fábrica de chocolate. Rio de janeiro: Martins Fontes, 2010.

FREIRE, Paulo. Pedagogia da autonomia, saberes necessários à prática educativa. São Paulo: Paz e Terra, 2011.

LOBATO, Monteiro. Reinações de Narizinho. Rio de Janeiro: Brasiliense, 2005.

ORTHOF, Sylvia. Mudanças no galinheiro mudam a vida por inteiro. Rio de Janeiro: Rovelle, 2012.

QUEIRÓS, Bartolomeu Campos de. Sobre ler, escrever e outros diálogos. Belo Horizonte: Autêntica, 2012

O peixe e o pássaro. Belo Horizonte: Editora Miguilim, 1974.

Pedro, o menino que tinha o coração cheio de domingo. Belo Horizonte: Editora Miguilim: 1995.

Mário, de pedras, conchas e sementes. São Paulo: Global, 2009. 1984.

Ciganos. Belo Horizonte: Editora Miguilim, Minerações. Belo Horizonte: RHJ, 1991. De não em não. São Paulo: Global, 2009. 2007. Sei por ouvir dizer. Porto Alegre: Edelbra, Menino inteiro. São Paulo: Global, 2008.

QUEIROZ, Rachel de. O quinze. Rio de Janeiro: José Olympio, 1982.

ROCHA, Ruth. O que os olhos não vêem. Rio de Janeiro Salamandra, 2003.

ROSA, Guimarães. Grande sertão veredas. Rio de Janeiro: Nova Fronteira, 2010.

REVISTA PALAVRA, Publicação SESC, 2012.

\section{COMO CITAR ESSE ARTIGO}

FERREIRA, Hellenice; LEMOS, Anna Paula Soares. A LEITURA LITERÁRIA COMO SABER INTERDISCIPLINAR: CONSIDERAÇÕES A PARTIR DA PROSA POÉTICA DE BARTOLOMEU CAMPOS DE QUEIRÓS. Signo, Santa Cruz do Sul, v. 43, n. 78, nov. 2018. ISSN 1982-2014. Disponível em: $<$ https://online.unisc.br/seer/index.php/signo/article/view/12133>. Acesso em: doi: https://doi.org/10.17058/signo.v43i78.12133. 